\title{
Finite element tyre model for antilock braking system study
}

\section{Fatemeh Yazdandoost*}

Department of Mechanical Engineering, 445 Goodwin Hall, Virginia Tech (MC 0238),

635 Prices Fork Road,

Blacksburg, VA 24061, USA

Email: fatemehy@vt.edu

${ }^{*}$ Corresponding author

\section{Saied Taheri}

Center for Tire Research,

Department of Mechanical Engineering, Randolph Hall 100C, Virginia Tech (MC 0710), 460 Old Turner Street, Blacksburg, VA, 24061, USA

Email: staheri@vt.edu

\begin{abstract}
In the present work a 235/75R15 tyre 3D finite element (FE) model was developed using the commercial software package ABAQUS. The finite element model considers the severe nonlinearities due to a tyre's complicated geometry, hyperelastic properties of the rubber material, contact between the tyre and the road, and the reinforcing bars inside the tyre's structure. The FE model was utilised to implement a braking event of antilock braking system (ABS) controller logic. The ABS controller was developed based on a commercially available system and the logic was coded in Fortran 77 and implemented in a UVAMP ABAQUS subroutine. The detailed 3D tyre model and the FE ABS model are discussed in detail. The results show that the ABS logic is capable of maintaining the minimum slip ratio to avoid tyre sliding.
\end{abstract}

Keywords: ABS; antilock braking system; finite element modelling; tyre; ABAQUS; dynamic explicit solver; VUAMP subroutine; hyperelastic; reinforcing elements; tyre road contact; slip ratio.

Reference to this paper should be made as follows: Yazdandoost, F. and Taheri, S. (2016) 'Finite element tyre model for antilock braking system study', Int. J. Vehicle Design, Vol. 72, No. 3, pp.248-261.

Biographical notes: Fatemeh Yazdandoost is a $\mathrm{PhD}$ candidate at the Department of Mechanical Engineering of Virginia Tech, Blacksburg, VA, USA. She graduated from MSc in Aerospace Engineering from Sharif University of Technology (SUT), Tehran, Iran. She is also a graduate of BSc in Mechanical Engineering from SUT, Tehran, Iran.

Saied Taheri is a Professor in the Department of Mechanical Engineering at Virginia Tech, Blacksburg, VA, USA. He is the Director of Center for Tire Research (CenTiRe). In several research projects funded by various government and non-government organisations, he has managed to develop the research tools necessary to model, analyse and implement tyre and vehicle 
related sensory systems, control algorithms, and hardware-in-the-loop simulation. His research and application experience in tyres as well as vehicles has also been applied to railroad problems, which is another area of interest.

\section{Introduction}

Since tyres perform as force generating and load transmitting mechanisms between the vehicle and the road, they are considered to be one of the most important components of a vehicle. Hence, the overall dynamic response of the vehicle is predominantly determined by tyre performance (Rao et al., 2006). The forces and moments generated in the tyre-road contact interface play a key role in handling and control of the vehicle during various operating conditions, e.g., during braking (Rao et al., 2006; Joy and Hartley, 1953). Without accurately determining the values for these dynamic interactions, designing accurate vehicle chassis control systems is impossible. Various empirical (Pacejka and Bakker, 1992; Pacejka and Besselink, 1997; Besselink et al., 2010; Braghin and Sabbioni, 2010), physical (Bernard et al., 1977; Guo and Lu, 2007) and semi-empirical tyre models (Schmeitz, 2004; Allen et al., 2008; Schmeitz et al., 2007) have been used in the past, in order to simulate tyre responses during different input conditions.

Finite element method (FEM) has provided a powerful tool to simulate highly detailed tyre models which have resulted in more accurate studies on tyre performance than the physics-based tyre models. Although FEM simulations require heavy computational analysis, the advances in computing technologies have enabled performing large amounts of computations in a very short time. Commercial finite element analysis (FEA) software programs e.g., LSDyna (Kao and Muthukrishnan, 1997), ABAQUS (Sobhanie, 2003; Rao et al., 2006), or PAM-SHOCK (Kamoulakos and Kao, 1998; Chae et al., 2004) have been widely used to generate FE tyre models. Some efforts have been made to utilise the FEM simulations in order to parameterise different tyre models. For example, Rao et al. (2006) developed a method to predict the magic formula (MF) parameters using ABAQUS. Balaramakrishna and Kumar (2009) used ABAQUS to estimate the short wavelength intermediate frequency tyre (SWIFT) model parameters for a passenger car tyre. More detailed FE models were simulated (Cho et al., 2004, 2005) using ABAQUS. The models comprised detailed tread blocks and were used for static tyre analysis (e.g., inflation and footprint) and short time dynamic analysis (e.g., rolling over a cleat). Various detailed FE tyre models that have been developed and used in the past are suitable for simulating tyre response in short transient events. However, in order to be able to perform an FE dynamic analysis in relatively long time events (e.g., braking) the models with large degrees of freedom (DOF) are not suitable.

Modelling antilock braking system (ABS) performances considering the dynamics of the tyres has been of a concern to tyre researchers (Sivaramakrishnan, 2013, 2014). Rigid ring tyre models have been utilised to examine the brake torque variations (Zegelaar and Pacejka, 1997) and performance of ABS (Jansen et al., 1999). MF-SWIFT model was also implemented in a full vehicle with ABS in order to study the braking response of a vehicle (Pauwelussen et al., 2003). In addition to analytical models, FE models were also considered to perform ABS braking simulations. Dymola and ABAQUS were utilised in a co-simulation by Schofield et al. (2009) in order to simulate 
a hydraulic ABS. In that simulation, a full 3D FE tyre model was developed in ABAQUS and assembled to a 3D FE model of a braking disk. In addition, a simple slip-control based ABS hydraulic braking pressure system was modelled in Dymola. For the control system in Dymola to command the brake control, the translation and rotational velocities of the wheel were measured and used for longitudinal slip calculations.

In the present study, ABAQUS/Explicit solver was used to develop a 3D axisymmetric rolling tyre model. The FEM started with a 2D axisymmetric model and finally resulted in a $3 \mathrm{D}$ full tyre model. A commercially available ABS controller logic was implemented inside ABAQUS using a developed UVAMP Fortran subroutine. The subroutine was used to setup an input/output channel between the FE tyre model and the ABS controller logic. UVAMP subroutine enables coupling of engineering controller systems with FE models (Abaqus, 2009). Utilising this controller/FEM coupling technique eliminates the need for use of other software programs (e.g., Dymola, etc.) in order to implement control logics into detailed finite element models of tyres. This method is promising to study how the dynamic response of the tyre structure is affected by the control parameters (e.g., ABS, traction control, etc.).

\section{Method}

In order to couple an ABS controller algorithm with an FE tyre model and subsequently, model an ABS braking event, a transient dynamic tyre model is required. Finite element modelling of a tyre consists of various material and structural nonlinearities such as the materials' hyper-elasticity, embedded reinforcing bars, large deformations, and contact implementation. This section covers the development of the FE tyre and ABS models.

\subsection{Finite element model}

\subsubsection{First step - 2D axisymmetric model}

In this research, a 235/75 R15 radial tyre was used to develop the FE model. In order to reduce the cost of the simulation, a common geometry simplification was considered in modelling, where the tread pattern blocks were simplified in the model. In addition to a reduction in the DOF of the $3 \mathrm{D}$ tyre model, this simplification enables the tyre geometry to be treated as an axisymmetric deformable solid object. This assumption provides the opportunity to start the modelling with a relatively simple $2 \mathrm{D}$ axisymmetric FE model of the cross section as the first step. Applying inflation pressure, which is inherently an axisymmetric loading from inside the tyre, was also considered in this step. To further accelerate the simulation, only one half of the cross section was modelled in this step and the simulation results were mirrored in the subsequent modelling steps.

Figure 1 shows the 2D axisymmetric model developed in the first step. In order to obtain the detailed cross-section geometry of the tyre, a real tyre was cut through the cross-section. Subsequently, the cut section was photographed and the image was processed thoroughly to ensure the quality of the obtained cross-section image. The captured photo was then imported in AutoCAD software and the geometry of the cross-section was re-drawn in CAD, emphasising the different parts of the tyre. Then, 
the CAD drawing was exported to the ABAQUS pre-processor. Different parts of the tyre were sectioned according to the finalised drawing. The locations for embedding the reinforcing elements were also determined. The cross-section was finely meshed to consider the maximum agreement with the real geometry. This fine mesh reduced the three-node elements and captured the stress gradients through the thickness of the tyre to introduce an accurate contact patch in the subsequent 3D FE analyses. Reinforcement parts were meshed as two-node 2D axisymmetric elements and embedded into the host elements.

Figure 1 One half of the cross section, including rubber and reinforcing parts of a 235/75 R15 radial tyre, used in 2D axisymmetric modelling. Different parts, possessing different material properties, are painted in different colours (see online version for colours)

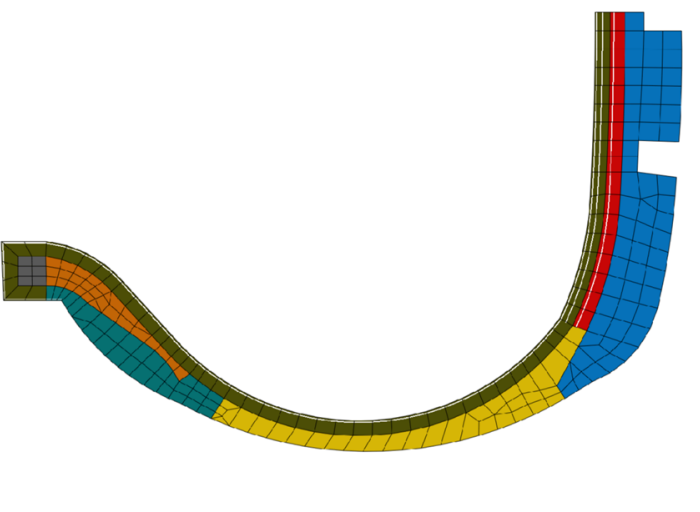

The element-node assignments and the node coordinates were extracted from the ABAQUS pre-processor, and the three-node elements were given an extra node to be formulated as 2D axisymmetric four-node elements. As shown in Figure 1, six hyperelastic material types were assigned to the rubber elements: filler, rim strip, sidewall, ply, belt, and tread. Table 1 lists the Yeoh constants for hyperelastic material properties assigned to the above-mentioned tyre materials. The material properties were taken from (Balaramakrishna and Kumar, 2009).

Table 1 Hyperelastic (Yeoh model) material properties of different tyre parts

\begin{tabular}{lcccc}
\hline Tyre region & $C^{l}\left(\mathrm{~N} / \mathrm{m}^{2}\right)$ & $C^{2}\left(\mathrm{~N} / \mathrm{m}^{2}\right)$ & $C^{3}\left(\mathrm{~N} / \mathrm{m}^{2}\right)$ & Density $\left(\mathrm{kg} / \mathrm{m}^{3}\right)$ \\
\hline Tread & $7.77561 \times 10^{5}$ & $-2.76138 \times 10^{5}$ & $9.5427 \times 10^{4}$ & 1178 \\
Side wall & $4.73685 \times 10^{5}$ & $-1.19853 \times 10^{5}$ & $3.4293 \times 10^{4}$ & 1118 \\
Rim strip & $6.66402 \times 10^{5}$ & $-2.08725 \times 10^{5}$ & $6.5205 \times 10^{4}$ & 1153 \\
Belt & $10.24719 \times 10^{5}$ & $-4.27524 \times 10^{5}$ & $1.73328 \times 10^{4}$ & 1198 \\
Ply & $4.79895 \times 10^{5}$ & $-1.35723 \times 10^{5}$ & $4.3677 \times 10^{4}$ & 1177 \\
Filler & $10.42176 \times 10^{5}$ & $-3.91161 \times 10^{5}$ & $1.34412 \times 10^{4}$ & 1204 \\
\hline
\end{tabular}

REBAR technique was used to introduce the reinforcing elements into the $2 \mathrm{D}$ tyre model. Two-node reinforcing elements were embedded inside the four-node rubber elements. The reinforcing materials were considered to be elastic isotropic and their material property constants are listed in Table 2 . The reinforcement cross-sectional areas, their 
spacing and their corresponding angles are listed in Table 3. The information in Tables 2 and 3 was taken from (Balaramakrishna and Kumar, 2009).

Table 2 Material properties of different reinforcements

\begin{tabular}{lccc}
\hline Reinforcement & Young's modulus $(\mathrm{Pa})$ & Poisson's ratio & Density $\left(\mathrm{kg} / \mathrm{m}^{3}\right)$ \\
\hline Bead & $2.06555 \times 10^{11}$ & 0.3 & 7570 \\
Ply & $4.93515 \times 10^{9}$ & 0.49 & 1068 \\
Belt & $2.18158 \times 10^{11}$ & 0.3 & 7618 \\
Chafer & $1.725 \times 10^{9}$ & 0.49 & 940 \\
\hline
\end{tabular}

Table 3 REBAR characteristics of reinforcing elements

\begin{tabular}{lccc}
\hline Reinforcement & Cross-sectional $\left(\mathrm{m}^{2}\right)$ & Spacing $(\mathrm{m})$ & Angle $(\mathrm{deg})$ \\
\hline Ply & $3.52257 \times 10^{-7}$ & $9.652 \times 10^{-4}$ & -2.28 \\
Belt & $1.96128 \times 10^{-7}$ & $1.47828 \times 10^{-3}$ & -66.7 \\
Chafer & $3.39999 \times 10^{-7}$ & $1.40462 \times 10^{-3}$ & 44.6 \\
\hline
\end{tabular}

In order to model the rim, rigid solid two-node axisymmetric elements were defined on the left most nodes of the cross section (Figure 1). The rim elements then, were tied to another node (called rim node) defined in the centre point of the tyre, which is placed on the line of axisymmetry. As boundary conditions, the rim node was fixed in all directions while the top most nodes were fixed in perpendicular directions. To complete the first step and to induce stress inside the tyre, inflation pressure of $2.2 \mathrm{kPa}$ was applied to the inner surface of the ply.

\subsubsection{Second and third step - 3D tyre model subjected to a vertical load}

A $3 \mathrm{D}$ model of one half of tyre was generated via rotating the $2 \mathrm{D}$ model around the rim. An analytical rigid surface was also created to present the road (Figure 2(a)). A frictionless contact was defined between the half-tyre model and the road surface. In addition to a vertical load of $2157 \mathrm{~N}$, which was applied to the rim node, the same inflation pressure as in the first step $(2.2 \mathrm{kPa})$ was also applied. Running the simulation resulted in a full contact between the tyre and the road. After the second step, the whole model (including the half-tyre contacted with the road and the simulation results) was mirrored in a new simulation to make a full 3D tyre model (third step). All the inputs of the second step remained the same for third step, except for the vertical load, which was doubled $(4314 \mathrm{~N})$. Figure 2(b) illustrates the full 3D tyre model. It is worth mentioning that all the 2D two-node shell and 2D four-node solid axisymmetric elements used in the first step were automatically transformed to be 3D four-node shell and 3D eight-node solid elements respectively after running the second step.

\subsubsection{Fourth step - steady state dynamics}

The first three steps were static simulations. In order to find the loaded radius of the tyre, and the corresponding free rolling speed, a steady state dynamic simulation, which is a semi-static analysis, was performed. In this step, the 3D tyre model was imported from 
the previous step. The same loading as in the previous step was maintained in this step. For defining the coefficient of friction, the exponential decay model of equation (1) suggested by Abaqus (2009) was used:

$$
\mu=\mu_{k}+\left(\mu_{s}-\mu_{k}\right) e^{-d_{c} \dot{\gamma}_{e q}}
$$

where $\mu$ is the Coulomb friction coefficient, $\mu_{k}$ is the kinetic friction coefficient, $\mu_{s}$ is the static friction coefficient, $d_{c}$ is a decay coefficient, and $\dot{\gamma}_{e q}$ is the slip rate. The static friction, kinetic friction and decay coefficients were assumed to be $0.90,0.45$, and 0.50 respectively which is in agreement with the values used in the literature (Rao et al., 2006; Balaramakrishna and Kumar, 2009).

Figure 2 3D tyre models of second (a), and third (b) steps. Inflation pressure, vertical load and full static contact are implemented (see online version for colours)

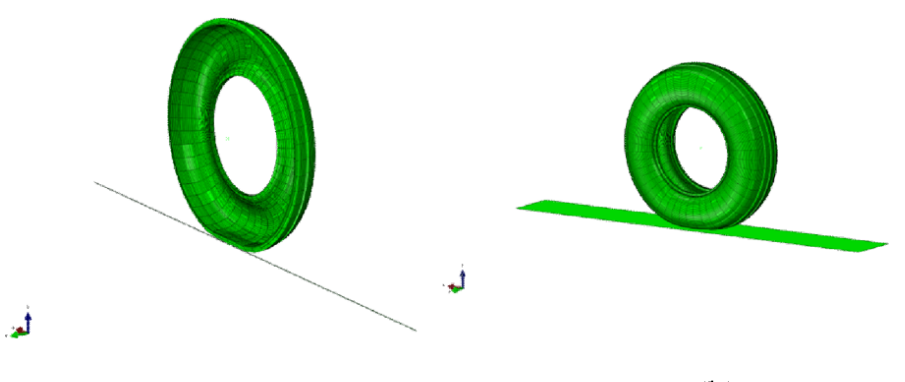

(a)

(b)

A translation speed of $11.165 \mathrm{~m} / \mathrm{s}$ was applied as a boundary condition to the centre node of the rim. Then, different trial values for rotational speed were exerted on the rim node as inputs in order to find the free rolling speed and the loaded tyre radius corresponding to the input rotational speed. In order to maximise the accuracy of the results, a Fortran subroutine code was utilised to do the try and error procedure. The subroutine applied trial angular velocities and measured the resultant rolling torque on the rim node. In order to maintain the free rolling condition, the torque should reach zero. The subroutine changed the input rotational speed several times to find the free rolling rotation speed corresponding to the zero rolling torque at the rim node.

\subsubsection{Fifth step - transient dynamic}

In order to simulate a dynamic event with a controllable input (e.g., braking torque) the dynamic explicit solver of ABAQUS is preferred. In this step, the free rolling translation and rotational velocities of the centre node of the rim, achieved from the previous step, was applied as initial conditions to the simulation. The same inflation pressure, vertical load and road contacts as in the previous simulation were applied for this step. The total time of $1.5 \mathrm{~s}$ was considered for the braking event. The outputs of this dynamic explicit simulation were stress components, velocities of the nodes, as well as contact forces and stress. An ABS controlled braking event was simulated, including a user subroutine for controlling the ABS braking torque. Time intervals of $10^{-4} \mathrm{~s}$ were assumed for capturing the results. The rim's rotational and translation velocities were considered as sensors for being utilised in the ABS controller Fortran subroutine code. 


\subsection{ABS simulation using VUAMP subroutine}

The braking torque, acting on the centre node of the rim, was one of the inputs to the dynamic explicit simulation of the FE model. As mentioned before, the linear and rotational velocities of the rim were defined as sensors in the model. The braking torque at the beginning of each time interval needed to be controlled by the ABS logic system.

The torque value was defined as an amplitude value in the simulation and this amplitude was controlled by an ABAQUS subroutine called VUAMP. This subroutine is suitable for modelling the control-engineering aspects of the system in a dynamic explicit FE model.

The ABS logic used in the present work is well explained in Sivaramakrishnan, (2013). Figure 3 illustrates the flow chart of this logic. As a summary, the controlling algorithm reads the translation and the rotational velocities of the wheel and calculates the slip ratio, defined in equation (2):

$$
\kappa=\frac{V_{x}-R_{l} \omega_{r}}{V_{x}}
$$

where $\kappa$ is the slip ratio, $V_{x}$ is the translation velocity, $\omega_{r}$ is the rotation velocity, and $R_{l}$ is the loaded tyre radius calculated in step four.

Based on the input, the algorithm determines the brake states and calculates the needed brake torque. The brake states considered in the algorithm could be listed as: initialise, hold brake pressure, increase brake pressure, fast increase brake pressure, decrease brake pressure, step increase brake pressure, step decrease brake pressure, and exit ABS braking (Sivaramakrishnan, 2013).

The controlling algorithm was coded in Fortran 77, which is the coding language for the ABAQUS subroutines. The subroutine code reads the sensor values, calculates the slip ratio, determines the brake state and gives the updating value for braking torque for continuing the FE simulation.

\section{Results and discussion}

Table 4 summarises the FE models of the different steps, the number of nodes and elements, the number of degrees of freedom, as well as the computation time required for running the simulations. Eight CPU cores were used for all the simulations.

Table 4 Finite element simulation parameters for different steps

\begin{tabular}{llcccc}
\hline $\begin{array}{l}\text { Step } \\
\text { number }\end{array}$ & Type & $\begin{array}{c}\text { Number of } \\
\text { elements }\end{array}$ & $\begin{array}{c}\text { Number of } \\
\text { nodes }\end{array}$ & $\begin{array}{c}\text { Number of } \\
\text { DOF }\end{array}$ & $\begin{array}{c}\text { Computation } \\
\text { time }\end{array}$ \\
\hline 1 & Static & 332 & 393 & 1179 & $2 \mathrm{~s}$ \\
2 & Static & 16898 & 20,834 & 59,484 & $7 \mathrm{~m}, 52 \mathrm{~s}$ \\
3 & Static & 33,794 & 41,330 & 117,948 & $43 \mathrm{~s}$ \\
4 & Steady state dynamic & 33,794 & 41,330 & 117,948 & $64 \mathrm{~m}, 34 \mathrm{~s}$ \\
5 & Transient dynamic & 33,794 & 41,330 & 117,948 & $26 \mathrm{~h}, 27 \mathrm{~m}$ \\
\hline
\end{tabular}


Figure 3 Antilock braking system algorithm flowchart (Sivaramakrishnan, 2013), $\kappa$ is slip ratio, and $V_{x}$ is translation velocity (see online version for colours)

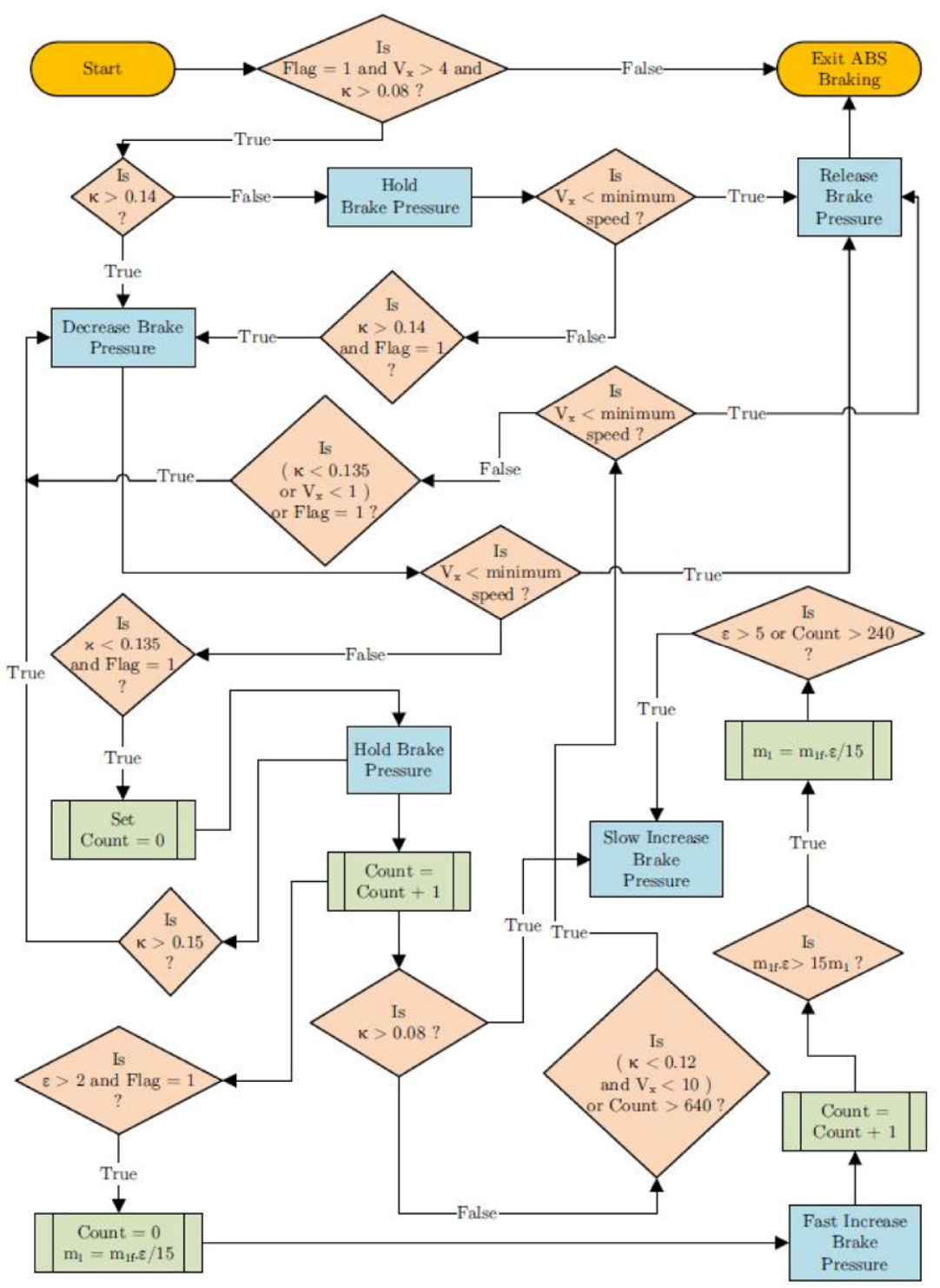

\subsection{Static simulations}

Figure 4 shows the contour plot of Von Mises stress after applying inflation pressure in the first step model. As expected, the reinforcing elements stand the maximum stress.

The second step includes transferring the axisymmetric inflation simulation into a $3 \mathrm{D}$ model and applying contact with the road. As mentioned in the previous section, the third step transfers the results of the second step and adds the other half of the tyre into the model. Figure 5 shows the stress distribution in the tyre cross section close to the contact region. As another result of this simulation, contact pressure distribution of the tyre 
with the road is plotted in Figure 6. It has to be mentioned that, in this static analysis, the tyre-road contact was considered to be frictionless.

Figure 4 Contour plot of Von Mises stress after applying inflation pressure in the first step model (see online version for colours)

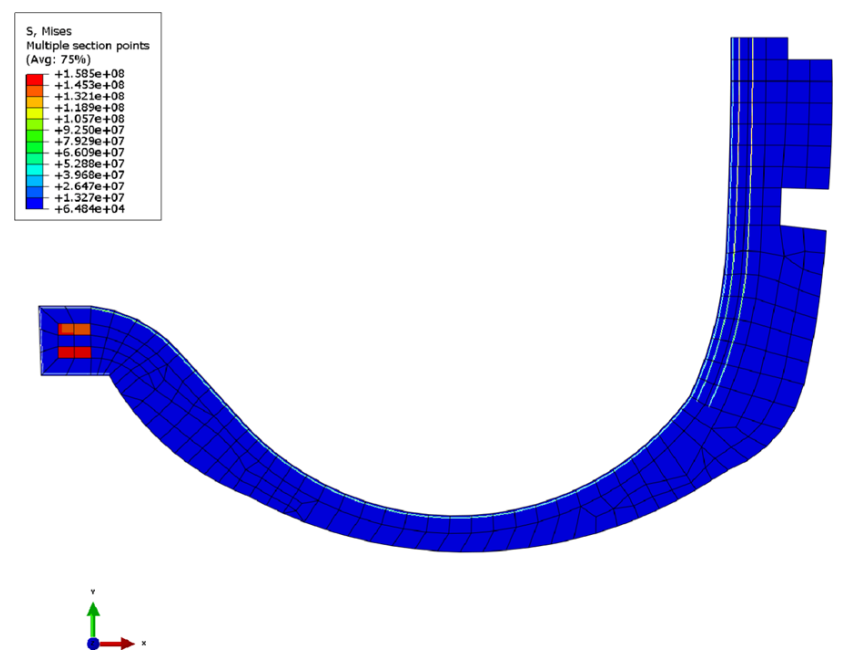

Figure 5 Stress distribution in the tyre cross section close to the contact region. Some elements are hidden in order to expose the stress distribution in the rebar elements (see online version for colours)

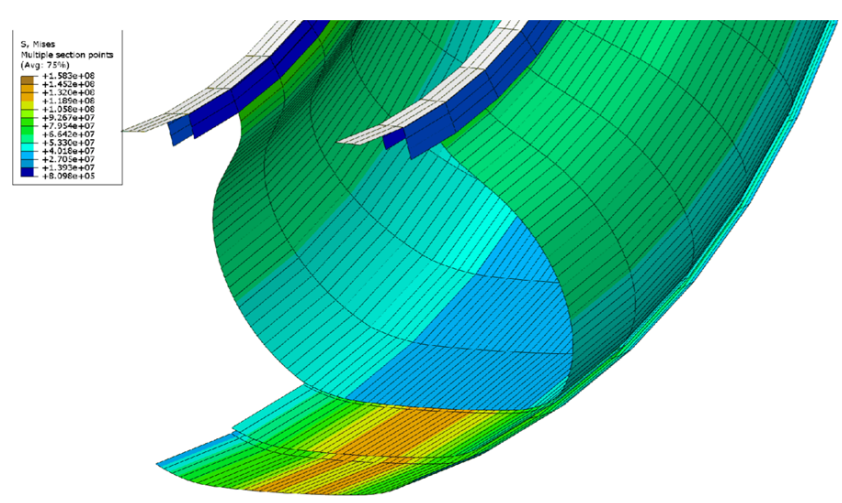

\subsection{Steady state dynamic simulation}

The free rolling translation and rotational velocities, resulting from the forth step simulation were calculated to be $11.165 \mathrm{~m} / \mathrm{s}$ and $28.268 \mathrm{rad} / \mathrm{s}$, respectively. The free rolling effective tyre radius was calculated to be $394.2 \mathrm{~mm}$.

The contact stress distribution of the quasi-static steady state dynamic model (forth step in free rolling) is plotted in Figure 7. Comparing the contact patch stress distributions of the static tyre (Figure 6) and the steady state rolling tyre (Figure 7) reveals that the contact patch area for both cases remains almost the same, but for the free rolling tyre simulation, the maximum pressure point moves forward in the direction of the tyre motion and its value is greater than the maximum pressure in the static tyre. 
Figure 6 Contact pressure distribution in contact patch of the static tyre simulation (step 3) (see online version for colours)

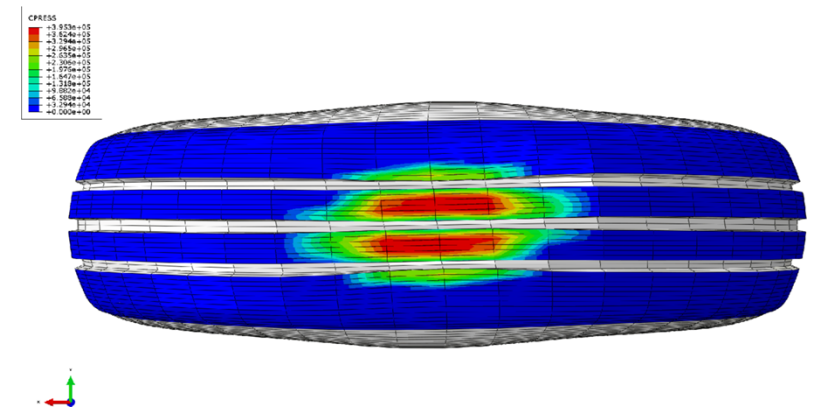

Figure 7 Contact pressure distribution in contact patch of the free rolling steady state tyre simulation (step 4) (see online version for colours)
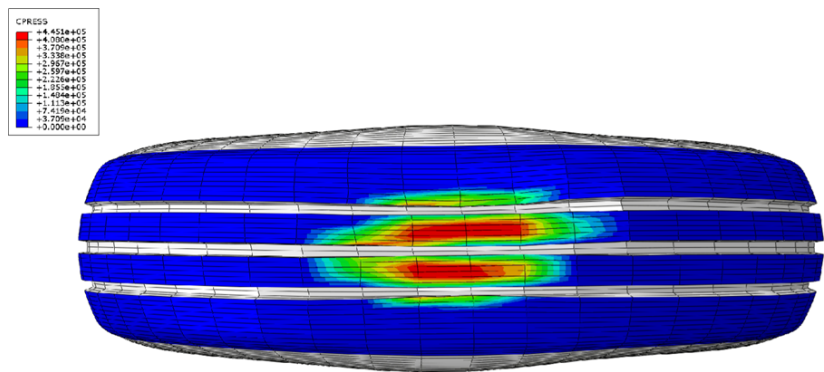

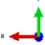

The free rolling velocities calculated in the fourth step were used as initial conditions for the transient dynamic tyre analysis.

\subsection{ABS simulation}

Utilising the VUAMP subroutine mentioned in Section 2.2, the input braking torque was calculated for all the time increments. Figure 8 shows the calculated ABS braking torque vs. time.

Figure 8 ABS controlled braking torque during the brake event (see online version for colours)

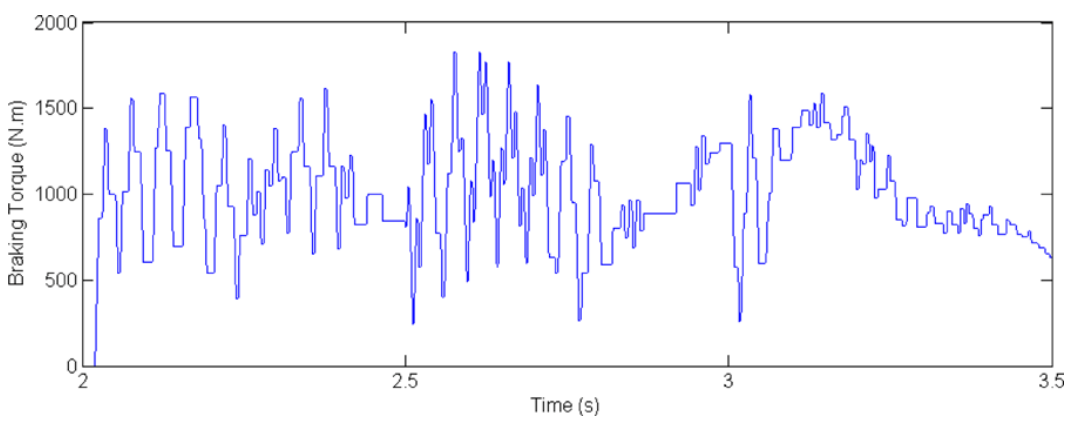


As a result of this varying braking torque, the translation and rotational velocities of the tyre reduced with time to illustrate an ABS controlled braking event. The circumferential velocity, which is rotational velocity multiplied by the loaded radius of tyre, and the translation velocity of the tyre as functions of time are plotted in Figure 9.

Figure 9 Translation and circumferential velocities of the tyre during the ABS controlled simulation (see online version for colours)

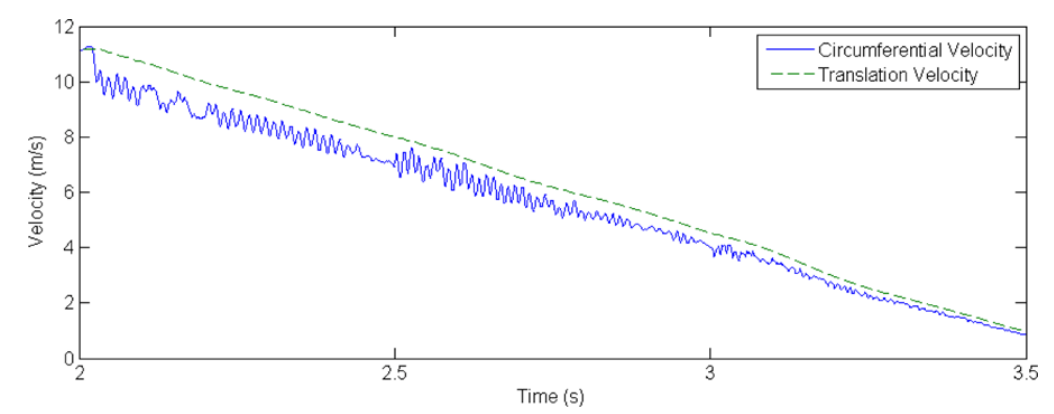

Inferred from the results of Figure 9, at the start of the simulation both velocities have the same value in order to illustrate a free rolling situation as the initial condition, but as the braking torque acts on the tyre, the circumferential velocity drops quickly and an almost constant difference between the two velocities is retained by the ABS controlling algorithm.

The slip ratio, which is defined as in equation (2), should remain low to prevent slippage of the tyre during the braking event. In other words, high slip ratio (close to 1) represents tyre locking which is in contrast with the purpose of ABS. Figure 10 illustrates the slip ratio values during the braking event, which is controlled to stay less than 0.135 for the most part. As the slip ratio increases, the ABS controller adjusts the braking torque in order to prevent the tyre from locking. As a result of these adjustments in the braking torque over the braking time, the road applies a variable longitudinal reaction force against the tyre motion. Figure 11 shows the road's longitudinal force and its associated slip ratio during the brake time.

Figure 10 Slip ratio during the brake event (see online version for colours)

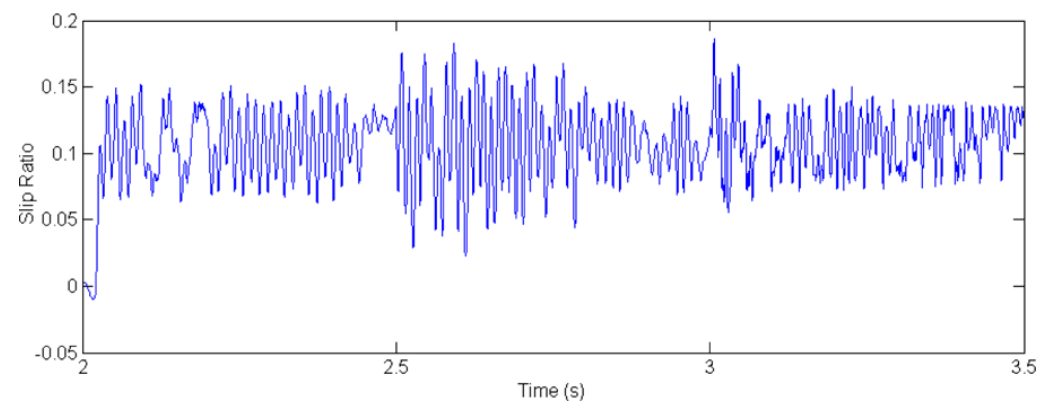

The ABS was successfully coupled to the FE model of the tyre, utilising a UVAMP ABAQUS subroutine. The method used in this study is promising to implement control logics into detailed finite element models of tyres. In addition to the antilock brake 
system, the same approach could be used to couple other controlled phenomena (e.g., traction control at an acceleration event) with FE tyre models.

Figure 11 The road's longitudinal reaction force and its associated slip ratio during the brake event (see online version for colours)

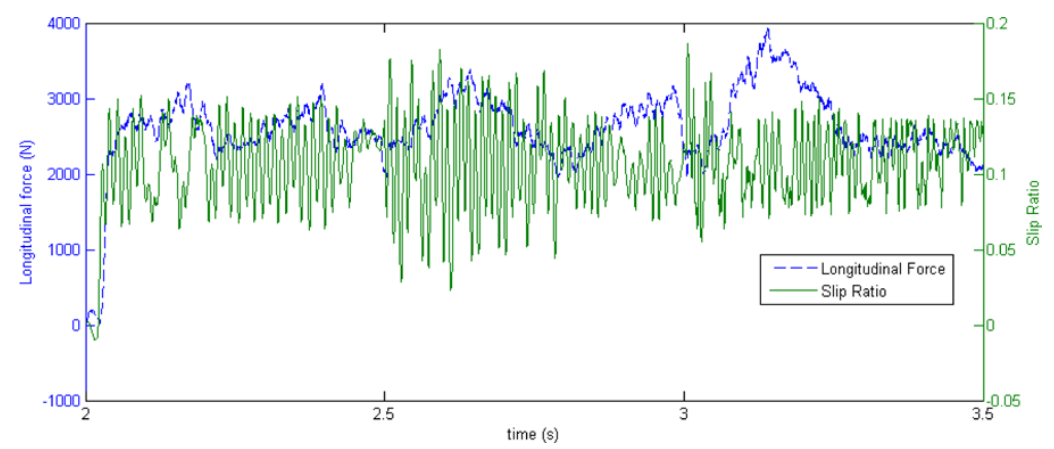

\section{Conclusion}

A 235/75R15 tyre 3D finite element model was developed using the commercial software package ABAQUS. A 2D axisymmetric tyre model was firstly developed for applying the inflation pressure. It was shown that the reinforcing bars carry the most portion of the stress during inflation. The model was rotated and then mirrored in order to generate a full 3D tyre model. The vertical load and the contact with the road were defined in this step. That model was then imported to a new steady-state dynamic model to find the loaded radius of the tyre and the free rolling translation/rotational combination. The tyre/road contact pressure distribution in static and dynamic states was also studied. Subsequently, the 3D tyre model in the ABAQUS/standard solver was exported to the ABAQUS/Explicit solver to simulate the tyre transient loading. An ABS controller logic was coded in Fortran 77 and implemented inside a UVAMP ABAQUS subroutine in order to simulate an ABS controlled braking event. The modelled FE transient rolling tyre was coupled with that subroutine and the ABS braking event was simulated. The detailed 3D tyre model was capable of stress analysis of the tyre under inflation, road contact and braking loadings. The final simulation demonstrated the ABS controlled adjusting braking torque during the event. It was shown that the method and the ABS logic were capable of maintaining a minimum slip ratio to avoid tyre sliding.

\section{References}

Abaqus, F. (2009) ABAQUS Analysis User's Manual, Dassault Systemes, Vélizy-Villacoublay, France.

Allen, J., El-Gindy, M. and Koudela, K. (2008) 'Development of a rigid ring quarter-vehicle model with an advanced road profile algorithm for durability and ride comfort predictions', ASME 2008 International Design Engineering Technical Conferences and Computers and Information in Engineering Conference, American Society of Mechanical Engineers, 3-6 August, Brooklyn, New York, USA, pp.583-590. 
Balaramakrishna, N. and Kumar, R.K. (2009) 'A study on the estimation of SWIFT model parameters by finite element analysis', Proceedings of the Institution of Mechanical Engineers, Part D: Journal of Automobile Engineering, Vol. 223, pp.1283-1300.

Bernard, J., Segel, L. and Wild, R. (1977) Tire Shear Force Generation during Combined Steering and Braking Maneuvers, SAE Technical Paper.

Besselink, I., Schmeitz, A. and Pacejka, H. (2010) 'An improved magic formula/swift tyre model that can handle inflation pressure changes', Vehicle System Dynamics, Vol. 48, pp.337-352.

Braghin, F. and Sabbioni, E. (2010) 'A dynamic tire model for ABS maneuver simulations', Tire Science and Technology, Vol. 38, pp.137-154.

Chae, S., El-Gindy, M., Trivedi, M., Johansson, I. and Öijer, F. (2004) 'Dynamic response predictions of a truck tire using detailed finite element and rigid ring models', ASME 2004 International Mechanical Engineering Congress and Exposition, 2004, American Society of Mechanical Engineers, pp.861-871.

Cho, J., Kim, K., Jeon, D. and Yoo, W. (2005) 'Transient dynamic response analysis of 3-D patterned tire rolling over cleat', European Journal of Mechanics-A/Solids, Vol. 24, pp.519-531.

Cho, J., Kim, K., Yoo, W. and Hong, S. (2004) 'Mesh generation considering detailed tread blocks for reliable 3D tire analysis', Advances in Engineering Software, Vol. 35, pp.105-113.

Guo, K. and Lu, D. (2007) 'UniTire: unified tire model for vehicle dynamic simulation', Vehicle System Dynamics, Vol. 45, pp.79-99.

Jansen, S.T., Zegelaar, P.W. and Pacejka, H.B. (1999) 'The influence of in-plane tyre dynamics on ABS braking of a quarter vehicle model', Vehicle System Dynamics, Vol. 32, pp.249-261.

Joy, T. and Hartley, D. (1953) 'Tyre characteristics as applicable to vehicle stability problems', Proceedings of the Institution of Mechanical Engineers: Automobile Division, Vol. 7, pp.113-133.

Kamoulakos, A. and Kao, B. (1998) 'Transient dynamics of a tire rolling over small obstacles-a finite element approach with PAM-SHOCK', Tire Science and Technology, Vol. 26, pp.84-108.

Kao, B. and Muthukrishnan, M. (1997) 'Tire transient analysis with an explicit finite element program', Tire Science and Technology, Vol. 25, pp.230-244.

Pacejka, H. and Besselink, I. (1997) 'Magic formula tyre model with transient properties', Vehicle System Dynamics, Vol. 27, pp.234-249.

Pacejka, H.B. and Bakker, E. (1992) 'The magic formula tyre model', Vehicle System Dynamics, Vol. 21, pp.1-18.

Pauwelussen, J., Gootjes, L., Schröder, C., Köhne, K.-U., Jansen, S. and Schmeitz, A. (2003) 'Full vehicle ABS braking using the SWIFT rigid ring tyre model', Control Engineering Practice, Vol. 11, pp.199-207.

Rao, K.N., Kumar, R.K., Mukhopadhyay, R. and Misra, V. (2006) 'A study of the relationship between magic formula coefficients and tyre design attributes through finite element analysis', Vehicle System Dynamics, Vol. 44, pp.33-63.

Schmeitz, A., Besselink, I. and Jansen, S. (2007) 'Tno mf-swift', Vehicle System Dynamics, Vol. 45, pp.121-137.

Schmeitz, A.J.C. (2004) A Semi-Empirical Three-Dimensional Model of the Pneumatic Tyre Rolling over Arbitrarily Uneven Road Surfaces, TU Delft, Delft University of Technology.

Schofield, B., Surendranath, H., Gäfvert, M. and Oancea, V. (2009) 'Interfacing abaqus with dymola: a high fidelity anti-lock brake system simulation', Proc. of the 7th Modelica Conf, 2009, 20-22 September, Como, Italy, pp.833-838.

Sivaramakrishnan, S. (2013) Discrete Tire Modeling for Anti-lock Braking System Simulations, MSc, Virginia Tech. 
Sivaramakrishnan, S., Siramdasu, Y. and Taheri, S. (2014) 'A new design tool for tire braking performance evaluations', ASME 2014 International Design Engineering Technical Conferences and Computers and Information in Engineering Conference, 2014, American Society of Mechanical Engineers, 17-20 August, Buffalo, New York, USA, pp.V007T05A012-V007T05A012.

Sobhanie, M. (2003) 'Road load analysis', Tire Science and Technology, Vol. 31, pp.19-38.

Zegelaar, P.W. and Pacejka, H.B. (1997) 'Dynamic tyre responses to brake torque variations', Vehicle System Dynamics, Vol. 27, pp.65-79. 